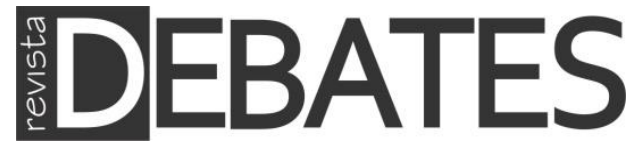

\title{
Frações do empresariado em campanha pró-Bolsonaro (2018)
}

\author{
Fractions of the business community that campaigned for Bolsonaro \\ (2018)
}

\section{Elaine de Almeida Bortone}

\section{Resumo}

A vitória de Jair Bolsonaro nas eleições de 2018 é resultado de inúmeros fatores, inclusive da ação de fraçóes do empresariado brasileiro. Este artigo tem como objetivo analisar os empresários/empresas que contribuíram para a eleição do candidato do Partido Social Liberal (PSL), bem como suas contribuiçóes a diversos candidatos à Câmara. A partir do início do século XX, a prática de empresários apoiarem seus representantes no universo político com a finalidade de obter benefícios econômicos tornou-se comum. Bolsonaro recebeu apoio do empresariado, e o seu governo o tem recompensado com políticas públicas favoráveis e com a indicação de alguns para cargos importantes. As referidas contribuiçóes, responsáveis pelo crescimento do candidato na campanha, se deram por meio de doações, coaçôes, disparos de fake news e apoios indiretos. O levantamento foi feito na imprensa e nos sites do Tribunal Superior Eleitoral (TSE) e do Ministério Público do Trabalho (MPT).

\section{Palavras-chave}

Jair Bolsonaro; Eleiçóes 2018; Empresariado.

\begin{abstract}
Jair Bolsonaro's victory in the 2018 elections is the result of numerous factors, including the action of fractions of the Brazilian business community. This article analyzes entrepreneurs that contributed to the election of the candidate of the Social Liberal Party, as well as their contributions to candidates for the House of Representatives. In the beginning of the 20th century, the practice of entrepreneurs supporting their representatives in the political world with the purpose of obtaining economic benefits became common. Bolsonaro received support from the business community, and his government has rewarded them with favorable public policies, as well as the appointment of some of them to important positions. These contributions, responsible for the candidate's growth in the campaign, took place through donations, coercion, fake news and indirect support. The survey was carried out in the press and on the websites of the Superior Electoral Court and the Federal Prosecutor Office for Labor Relations.
\end{abstract}

\section{Keywords}

Jair Bolsonaro; Elections 2018; Businessmen. 


\section{Introdução}

Com o impulso das atividades do setor industrial, a partir do início do século XX, época do desenvolvimento do capitalismo industrial, houve uma transformação no comportamento do empresariado, que passou a se interessar por outras questóes que diziam diretamente sobre seus negócios, passando a buscar espaços de poder no campo político para beneficiar seus próprios interesses econômicos. Mancuso (2004) aponta que a percepção de que as decisões do poder público têm o poder de interferir sobre as atividades das suas empresas levaram muitos empresários a desenvolver atividades de articulação de interesses.

O empresário, segundo Antônio Gramsci (2014, p. 15), representa uma elaboração social superior que "[...] deve possuir uma certa capacidade técnica, não somente na esfera restrita de sua atividade e de sua iniciativa, mas também em outras esferas, pelo menos mais próximas da produção econômica”. Nas outras esferas, exteriores à empresa, segundo o autor, o empresário organiza a sociedade em geral e o organismo estatal com a finalidade de criar as condiçóes mais favoráveis à expansão da sua própria classe.

Cardoso (1972) explica que o funcionamento do sistema capitalista mudou o perfil do empresariado. Os mecanismos de acumulação de capital, de obtenção de lucros, de inversão econômica e de utilização da capacidade empresarial redefiniram os empresários como categoria social. Nesse cenário, o empresário estrutura as possibilidades de ação e dá sentido aos projetos de realização econômica por meio de influência na política econômica, visando assegurar a prosperidade capitalista e reservar a maior porção dos contratos e privilégios para a sua classe.

Desde então, verificam-se empresários brasileiros atuando, individualmente ou por meio de suas entidades de classe, no apoio ou não a diferentes governos e regimes políticos e trabalhando para a ruptura com um Estado quando este não mais responde aos seus interesses. Essa atitude do empresariado de interferência, mobilização, articulação e de participação política se dá pela defesa das ideias liberais, dos lucros crescentes, da propriedade privada, do êxito capitalista, contra o comunismo e o socialismo (DINIZ, 1994).

Dentro da estratégia de participar diretamente das decisóes do Estado, os empresários passaram a ocupar cargos em postos estratégicos da administração pública. No governo ditatorial de Castello Branco (1964-1967), empresários que haviam financiado o golpe de Estado de 1964, por meio do Instituto de Pesquisas e 
Estudos Sociais (IPES) $)^{1}$, e legitimado a ditadura ocuparam treze dos quinze ministérios existentes, como também tornaram-se presidentes, vice-presidentes, diretores e conselheiros de empresas estatais federais de diferentes setores econômicos (BORTONE, 2018). A presença e a participação formal de fraçôes de classe nos aparelhos estatais, explica Bortone (2018), implicaram no controle do Estado e na garantia da sua influência sobre o processo decisório. A autora acrescenta que, ainda no primeiro governo ditatorial, foi criada uma série de políticas públicas que beneficiaram o empresariado, sobretudo do setor farmacêutico.

Mancuso (2004) aponta que o empresariado empenha recursos políticos à sua disposição em uma manipulação política, na qual as atividades econômicas ocorrem, para arrancar do poder público toda a sorte de vantagens particulares, tais como tratamento tributário favorecido, crédito subsidiado com taxas de juros diferenciadas, proteção especial contra a competição, entre outras. Em sua busca incessante por privilégios, explica o autor, o empresariado e as organizaçóes empresariais não têm nenhum interesse pelo impacto que as medidas defendidas porventura irão exercer sobre o público em geral.

Mancuso (2004) classifica cinco categorias de ação política realizadas pelo empresário para acompanhar o Legislativo: acompanhamento, análise, tomada de posição, orientação e pressão. A primeira diz respeito ao acompanhamento da tramitação das matérias de interesse do setor. $\mathrm{Na}$ segunda categoria, o empresário analisa detalhadamente cada uma das proposições legislativas. Posteriormente, adota posição diante de cada projeto, tendo como base a análise técnica. $\mathrm{Na}$ sequência, o empresário orienta a disseminar o resultado das análises técnicas das proposições legislativas. E, por fim, pressiona politicamente a articulação de interesses, ou seja, a apresentação de demandas aos tomadores de decisão.

Serna e Botinelli (2017), que analisam o poder das elites empresariais na América Latina, apontam que o surgimento do ciclo neoliberal alterou a arena política latino-americana, trazendo a influência política dos empresários sob as seguintes formas: protestos e revoltas corporativas; golpes de Estado; invasóes militares; eleiçôes com acomodaçôes de negócios para partidos ou candidaturas populistas; e nomeaçôes e governos conservadores. Segundo os autores, os três

\footnotetext{
${ }^{1}$ O IPES (1961-1972) foi fundado por empresários, tecnocratas e militares para integrar os diversos grupos civis e militares em uma oposição que pudesse deter o governo de João Goulart (1961-1964) e as forças sociais que o apoiavam. Desenvolveu açóes e estratégias para desestabilizar e esvaziar o governo Goulart, que estava atingindo diretamente seus interesses econômicos (BORTONE, 2018).
} 
primeiros foram os mais comuns no passado, durante o autoritarismo militar e em períodos de crise. As últimas práticas políticas estão relacionadas às estratégias de adaptação a serem inseridas no jogo democrático, quando os empresários conseguiram se inserir na dinâmica das democracias como ator econômico e político para aumentar a visibilidade pública. Para os pesquisadores, o impulso do segundo ciclo de reformas neoliberais e sua politização na chave da oposição ideológica às alternativas populistas e socialistas, facilitou o aumento do poder político dos empresários. Com relação ao último grupo, há parlamentares de partidos de direita relacionados aos empresários. Este tipo de parlamentar está, por sua vez, relacionado a juízes, militares, grupos com perfil religioso e a vínculos com religióes protestantes e católicas.

A candidatura de Bolsonaro à presidência da República foi apoiada e financiada por fraçôes do empresariado, mais precisamente a burguesia comercial, do varejo, isto é, classe dominante que vive do capital. Conforme as falas do empresariado na imprensa, essa é uma burguesia que tem se mostrado conservadora, preconceituosa, homofóbica, machista, racista e rancorosa com a classe trabalhadora, conforme será discutido à frente. Essa burguesia gosta de explorar os trabalhadores com baixos salários e exibe práticas de repressão contra eles, conforme as coaçóes analisadas à frente; emprega um grande contingente de mão de obra e aposta na terceirização e no corte de direitos trabalhistas, conforme Bolsonaro anunciou que faria.

Não foi identificado se os empresários são evangélicos, católicos ou ateus, mas seguramente têm uma vinculação de ocasião com as expressões neopentecostais, expressamente por meio da teologia da prosperidade, conforme o Movimento Brasil 200, que enfatiza "valores" e "riqueza" como evidência de "sucesso" para o país. Serna e Botinelli (2017) explicam que os empresários que participam da política latinoamericana têm uma forte proximidade com os partidos de direita, com a religiáo e com as associações empresariais.

$\mathrm{O}$ artigo não tem como objetivo analisar os outros candidatos à presidência, apenas o que saiu vitorioso nas eleições de 2018 e que estará determinando o rumo do Estado até 2022.

\section{A campanha pró-Bolsonaro}

Segundo a imprensa, os empresários que apoiaram publicamente Bolsonaro foram: 
Quadro 1 - Empresários/Empresas que apoiaram Bolsonaro

\begin{tabular}{|c|c|}
\hline EMPRESÁRIOS & EMPRESAS \\
\hline Abílio Diniz & Carrefour $^{2}$ \\
\hline $\begin{array}{l}\text { Afrânio Barreira Filho e } \\
\text { Eugênio Veras Vieira }\end{array}$ & Coco Bambu ${ }^{3}$ \\
\hline Alberto Moreira Saraiva & Habib's $^{4}$ \\
\hline BraulioBacchi & Artefacto Móveis e Tecidos \\
\hline Cristiana Arcangeli & Phytoervas 5 \\
\hline Edir Macedo Bezerra & Grupo Record $^{6}$ \\
\hline Elie Horn & CyrelaBrazilRealty $^{7}$ \\
\hline Fábio Wajngarten & (articulador da burguesia) \\
\hline Flávio Gurgel Rocha & Grupo Guararapes $^{8}$ \\
\hline Gustavo Bebbiano Rocha & sócio da advogada MariannaFux \\
\hline José Marcelo Braga Nascimento & BNZ - Braga Nascimento e Zilio Advogados? \\
\hline José Salim Matar & Localiza $^{10}$ \\
\hline Júlio Bozano & Grupo Bozano \\
\hline Luciano Hang & Lojas Havan $^{11}$ \\
\hline Marcelo Pessoa & Galápagos Capital Gestora de Fundos ${ }^{12}$ \\
\hline
\end{tabular}

2 Península adquiriu participação acionária no capital do Carrefour Brasil. Em 2015, a Península adquiriu ações do Carrefour S.A., e, um ano depois, tornou-se a terceira maior acionista da companhia. Em 2016, Abílio foi nomeado membro do Conselho de Administração do Grupo Carrefour.

${ }^{3}$ yzzer.com agência de viagem, Coco Bambu Lounge \& Music, Coco Bambu For One.

${ }^{4}$ Ragazzo, Arabian Bread, Ice Lips, Promilat, Vox Line.

${ }^{5}$ Phytoervas Fashion, Beauty'in, apresentadora de programas da Record.

${ }^{6}$ Fundador da Igreja Universal do Reino de Deus (IURD).

7 Instituto Cyrela e Crescera Investimento, novo nome da gestora de recursos Bozano Investimento, empresa que é acionista e que tinha como sócio o ministro da Economia, Paulo Guedes (OLIVEIRA, 2019).

${ }^{8}$ Riachuelo, Midway Financeira, Transportadora Casa Verde, Confecçóes Guararapes, Shopping Midway Mall.

9 Presidente do Instituto Eu Amo o Brasil, que, com ajuda do prefeito de São Paulo, João Dória, espalha bandeiras do Brasil pela cidade de SP em troca da exposição de sua marca e do seu escritório de advocacia (SETO, 2018).

10 Omni Táxi Aéreo Ltda e da Pottencial Seguradora AS. É membro-executivo da Locapar Participaçóes e Administração Ltda., Sócio-gerente da Haras Sahara Ltda., Sócio-gerente da SM Participações e Administração Ltda. e Sócio da Mattar Participações Ltda. Responsável pela operação da Hertz no Brasil (MACIEL, 2019a).

${ }^{11}$ Tecelagem Santa Cruz.

${ }^{12}$ Marcelo Pessoa é sócio fundador da GME4 Mineração (Global Mining Exploration), uma empresa de mineração fundada em 2007. A empresa explora calcário em Santa Maria da Vitória - BA e minério 


\begin{tabular}{|l|l|}
\hline Mário Gazin & Grupo Gazin $^{13}$ \\
\hline Meyer Joseph Nigri & Tecnisa Engenharia \\
\hline Rubem Menin & MRV Engenharia ${ }^{14}$ \\
\hline Rubens Ometto Silveira Mello & Grupo Cosan ${ }^{15}$ \\
\hline Sebastião Vicente Bomfim Fo & Grupo SBF - Centauro \\
\hline Silvio Santos & Grupo Silvio Santos \\
\hline Takashi Nishimori & Planagri Emp. Agropecurário e Brudden Equipamentos \\
\hline Victor Vicenzza & Victor Vicenzza $^{17}$ \\
\hline Washington Cinel & Gocil \\
\hline
\end{tabular}

Fonte: Adaptado de Desidério (2018) e Pablito (2018).

Com exceção de Meyer Joseph Nigri, José Salim Matar, Rubens Ometto Silveira Mello e Abílio Diniz, que possuem empresas de grande porte, os empresários fazem parte de setores da burguesia comercial e possuem empresas de pequeno e médio porte.

Segundo suas falas, os empresários não se mostraram preocupados com as acusaçôes de racismo, homofobia, misoginia e apologia ao regime militar associadas à Bolsonaro (GIELOW, 2018). Conforme Meyer Nigri, "Ele pode falar o que não deve, mas se fizer o que deve, não tem problema" (BECKER e OLIVEIRA, 2018). Essa afirmação mostra que o empresariado não tem partido político, não se preocupa com as distinções entre os sistemas políticos e geralmente aceita o status quo, quer seja autoritário ou democrático, desde que seus interesses não sejam ameaçados. $\mathrm{O}$ empresariado deseja um candidato que lhe propicie estabilidade em relação aos investimentos mais do que quaisquer valores democráticos de oposição, contestação pública ou competição política.

de ferro no Piauí e em Minas Gerais, na cidade de Ipatinga. Site oficial da Galapago: $<$ https://galapagoscapital.com/>.

${ }^{13}$ UniGazin- Universidade Corporativa Gazin, Gazin Colchôes (ind.), Consórcio Nac. Gazin, Gazincred S/A, Gazin Auto Posto, Gazin Viagens, Paranatec, agronegócio.

${ }^{14}$ Canal CNN Brasil.

${ }^{15}$ Usina Barra Bonita, Exxon Mobil do Brasil, Rumo Fusão All (logística), Radar (gestão de terras), Nova América (açúcar União), Raízes Combustível (joint venture entre a Cosan e a Shell), Raizen Energia (Usina Sta. Cândida e Paraíso), Comgás, Logum, CommaOil, Cosa Logística, Cosan Biomassa, Moove, CosanLimited.

${ }^{16}$ Centauro, ByTenis, Almax Sports, Nike Store (operador-representante no Brasil).

${ }^{17}$ SBT - Sistema Brasileiro de Televisão, Liderança Capitalização, Jequiti Cosméticos e TV Alphaville.

${ }^{18}$ GOCIL, uma das maiores empresas de segurança do país. LIDE Segurança, braço da LIDE Liderança Empresarial de João Dória, Villa Oliva Rice, com plantações de arroz no Paraguai. 
Os empresários citados apoiavam o candidato por diferentes motivos. Uns afirmavam que o Brasil havia virado um país socialista, o que o tornava difícil para os empresários, e o candidato faria as mudanças necessárias (DESIDÉRIO, 2018). Outros acreditavam que o capitão reformado do Exército entendia de segurança e de fronteiras e estava comprometido com o Estado de Israel (LESSA, 2018). Alguns asseguravam que Bolsonaro iria romper com o "modelo que está aî" e mudaria as leis trabalhistas (DESIDÉRIO, 2018). Diversos se identificavam com a sua ideologia (DESIDÉRIO, 2018). Rubens Ometto Mello apoiou o candidato do PSL esperando a aprovaçáo da Reforma da Previdência, sem a qual, segundo o empresário, o "[...] país vai ficar insolvente no médio prazo" (GARCIA, 2018).

Os empresários afiançavam que o candidato era honesto, o que o tornava "[...] raro para um político" (LESSA, 2018), embora alguns desses empresários estivessem envolvidos com corrupção e outros crimes, tais como: Rede Coco Bambu foi condenada por plagiar o cardápio de um concorrente (REDE..., 2018); Luciano Hang foi condenado por sonegação fiscal, evasão de divisa e sonegação de INSS (NUNES e FIORATTI, 2018); uma das subsidiárias do Grupo Cosan possuía pelo menos R \$ 6,3 milhões de dívidas tributárias com a União; a Agropecuária Itapiru, empresa registrada no nome de Rubens Ometto Silveira Mello, também devia R\$1,5 milhão, de acordo com o cadastro da dívida ativa da Procuradoria Geral da Fazenda Nacional (PGFN) (REBELLO e PRAZERES, 2018).

Buscando mais apoio, Bolsonaro teve algumas reuniōes com outros empresários para se apresentar como nome comprometido com o ideário liberal na economia e conquistar, assim, a classe empresarial na sua empreitada eleitoral.

Assumidamente, Bolsonaro não entende de economia (GRILLO, MENEZES e PRADO, 2018). Para se preparar para as reuniôes com o empresariado, recebeu instruções de Paulo Guedes e dos economistas Abraham Weintraub (FGV) e Arthur Weintraub (UNIFESP), que faziam parte do grupo montado por Guedes para apoiar o presidenciável. Na ocasião, o candidato justificou: "Não vou aprender em um curso intensivo de economia, mas sei falar em um nível macro com o Paulo Guedes, assim como converso de Forças Armadas com o general Augusto Heleno" (BOLSONARO..., 2018a).

Acompanhado do filho Eduardo e de Frederico d'Ávila, diretor da Sociedade Rural Brasileira (SRB), Bolsonaro se reuniu com empresários, em julho de 2018, na Península, empresa de Abílio Diniz, quando defendeu cortes de gastos públicos para atrair investidores. Estavam presentes Candido Bracher (Itaú Unibanco), David 
Feffer $^{19}$ (Suzano), José Roberto Ermírio de Moraes (Votorantim), Pedro Wongtschowski (Grupo Ultra) e Marcelo Martins (Cosan). Após a reunião, os empresários avaliaram que o militar falou com fluidez sobre segurança pública, sua principal bandeira, mas de maneira "simplista" sobre outros temas. Não deixou boa impressão, conforme os presentes, ao dizer que não precisava entender de economia para ser presidente. Ficaram preocupados com a falta de uma agenda econômica consistente do pré-candidato (BOLSONARO..., 2018a).

Em agosto, Luciano Hang reuniu em um café da manhã 62 empresários, entre eles: Candido Bracher (Itaú Unibanco), David Feffer (Suzano), José Roberto Ermínio de Morais (Votorantim), Flávio Gurgel Rocha (Grupo Guararapes), José Salim Mattar (Localiza), Meyer Joseph Nigri (Tecnisa), Sebastião Vicente Bomfim Filho (Grupo SBF), Bráulio Bacchi (Artefacto) e Fábio Wajngarten (BECKER e OLIVEIRA, 2018). Ainda estavam presentes Eduardo Bolsonaro, Major Olímpio e o general Augusto Heleno. $\mathrm{Na}$ ocasião, os empresários mostraram que as suas preocupações eram os partidos de esquerda, aos quais creditavam uma vocação "comunista". Meyer Joseph Nigri afirmou: "[...] apoio quem seja contra a esquerda, Bolsonaro, Alckmin ou qualquer outro" (BECKER e OLIVEIRA, 2018).

Luiz Antônio Nabhan Garcia, presidente da União Democrática Ruralista (UDR), relatou na reunião que realizou uma caravana no interior de São Paulo em prol do candidato. Em um evento, em julho, no Pará, o pecuarista aproveitou para pedir a Bolsonaro: "Quando o senhor se tornar presidente, vê o que fará com essa gente da FUNAI, do IBAMA, do Ministério Público, que não respeitam a propriedade privada" (BECKER e OLIVEIRA, 2018).

Luciano Hang, com o objetivo de instigar o empresariado a participar da campanha, assegurou que a falta de presença de empresários na vida política do país no passado foi responsável pela situação atual do país: “[...] a falta de entrosamento político da classe empresarial levou o país à situação em que nos encontramos hoje. Houve uma terceirizaçáo da política a pessoas de mau caráter, corruptas, comunistas, socialistas e vigaristas" (BECKER e OLIVEIRA, 2018).

Ainda em agosto, foi realizado outro encontro de Bolsonaro com o empresariado, em Porto Alegre (RS), promovido pela Revista Voto, que o apresentou como "alternativa ética da eleição presidencial" (BOLSONARO..., 2018b).

${ }^{19}$ Cia Suzano de Papel e Celulose, sob o comando de Leon Feffer, financiou o Instituto de Pesquisas e Estudos Sociais (IPES) no início dos anos 1960. 
encontro teve como patrocinadores: Carrefour, FM Logistec e Souza Cruz (BOLSONARO..., 2018b). Estavam presentes: Jorge Gerdau (Gerdau), Otelmo Drebes (Lojas Lebes), Cleber Benvegnù (Casa Civil do governo), Paulo Argolo e Luis Pedro Cauduro Ferreira (Dana), André Rocatto (Federasul, Fecomércio, Agas, Sindifumo), Karim Miskulin (Voto), Fernando Bomfiglio (Souza Cruz), Carmen Flores (Presidente do PSL-RS e Carmen Flores Imóveis) e Clenir Wengenowicz (TOK).

No episódio, Bolsonaro, em defesa da propriedade privada, criticou os movimentos sociais: "Temos de identificar as ações do MST (Movimento dos Trabalhadores Rurais Sem Terra) e do MTST (Movimento dos Trabalhadores Sem Teto) como terrorismo, buscando inibi-las na lei" (ZONA ELEITORAL..., 2018). Como medida para a redução do Estado brasileiro, o candidato afirmou: "Vamos extinguir de imediato as 50 estatais que o PT criou ao longo de 13 anos. A mais importante, que vem até de antes desse período, é a Empresa Brasil de Comunicação (EBC), que gasta R\$ 1 bilhão por ano para acomodar jornalistas de esquerda aposentados" (ZONA ELEITORAL..., 2018).

O deputado federal Onyx Lorenzoni (DEM), proprietário da Agropet Menino Deus (MASCARENHAS, 2019), introduziu o candidato na reunião e destacou que "[...] ele está conectado com uma demanda histórica da população brasileira" (BOLSONARO..., 2018b). Ainda, afiançou que “[...] há mais de 40 anos, este país espera a chance de poder ver as ideias liberais e conservadoras fazerem uma aliança e ter alguém que as simbolize. Nós, brasileiros, descobrimos que essas ideias têm um líder" (BOLSONARO..., 2018b).

$\mathrm{O}$ candidato à presidência recebeu outros apoios. As Lojas Americanas (Jorge Paulo Lemann) venderam camisetas pró-Bolsonaro e anti-Lula na sua página virtual. As pró-Bolsonaro, com estampas com a imagem de Bolsonaro armado em posição de herói e de "mito". Já as estampas contra Lula da Silva diziam "Xô, Lula" e "Fora, ladrão", debochadamente com o desenho da mão sem o dedo mínimo. As camisetas, que estimulavam o preconceito, também foram colocadas à venda em outras lojas virtuais, como Submarino e Shoptime, pertencentes à B2W (Marcio Cruz Meirelles), empresa de comércio eletrônico, que também é dona da Americanas.com. Posteriormente, após reação negativa, as vendas foram suspensas (LOJAS..., 2018).

A norte-americana Burger King (Jorge Paulo Lemann) lançou propaganda contra o voto em branco, exibida nacionalmente no intervalo do debate presidencial da Rede Record (TEIXEIRA, 2018). A publicidade chamava atenção por seu cunho político, posicionamento incomum para marcas estrangeiras no Brasil, que costumam 
se articular anonimamente e sorrateiramente, diferentemente dos empresários que se colocam publicamente.

A Rede Record (Edir Macedo) foi uma máquina de campanha para defender e promover o candidato do PSL. A rede ampliou a visibilidade de Bolsonaro com a disseminação de falas favoráveis de outros políticos e evitou críticas ao presidenciável. Vetou, por exemplo, a produção de reportagem sobre o capoeirista Romualdo Rosário da Costa, morto a facadas em Salvador (BA) por eleitor que defendia o candidato. Após apoio público do bispo nas redes sociais, Bolsonaro concedeu uma entrevista exclusiva à TV no mesmo dia e hora em que acontecia o debate com presidenciáveis na Rede Globo (FIORATTI, 2018). O candidato se ausentou do debate porque se recuperava de uma cirurgia, após ter sido esfaqueado, mas compareceu a outro compromisso.

O curso Estratégia Concursos (Brasília) lançou uma promoção de $12 \%$ de desconto, em referência à sentença de 12 anos de prisão decretada pelo Tribunal Regional Federal da 4a Região ao ex-presidente Lula: "A mortadela acabou, mas o desconto você ganhou". No mesmo anúncio, há ainda uma menção subliminar a Bolsonaro: "é melhor jair (sic) aproveitando" (SCRIVANO, 2018). O curso é de propriedade de Heber Carvalho, Mário Pinheiro e Ricardo Vale.

Após a definição da eleição presidencial, o Itaú Unibanco enviou uma carta pró-Jair Bolsonaro aos investidores do segmento do varejo e com alta renda (COTIAS, 2018).

Além dos empresários, entidades de classes de representação empresarial de diferentes setores apoiaram Bolsonaro, mostrando sua capacidade de mobilização, articulação e de participação política. George Teixeira Pinheiro, da Confederação das Associações Comerciais e Empresarias do Brasil (CACB), lançou manifesto de apoio ao candidato à Presidência. No campo religioso, a Confederação dos Conselhos de Pastores do Brasil estava com o militar. Produtores ligados à Associação Brasileira dos Produtores de Soja (APROSOJA), incluindo seu presidente, Bartolomeu Braz Pereira, declararam-se a favor do candidato. No Congresso, a Frente Parlamentar da Agropecuária (FPA) declarou apoio oficial a Bolsonaro (MATSUI, 2018). Conhecida como "bancada ruralista", a FPA reuniu 227 deputados federais e 27 senadores e tinha forte influência no Congresso Nacional. A deputada Tereza Cristina (DEMMS), presidente da FPA, foi visitar Bolsonaro, em sua casa, para formalizar o seu apoio (MATSUI, 2018). 
Bolsonaro recepcionou em sua casa, no Rio de Janeiro, as seguintes entidades de classe que foram declarar seus apoios: Abiquim (Associação Brasileira da Indústria Química)-Fernando Figueiredo; Abimaq (Associação Brasileira de Máquinas e Equipamentos); AEB (Associação de Comércio Exterior do Brasil) - José Augusto de Castro; Anfavea (Associação Nacional de Fabricantes de Veículos Aut.); ABIT (Associação Brasileira da Indústria Têxtil e de Confecção) - Fernando Pimentel; CBIC (Câmara Brasileira da Indústria de Construção); Instituto Aço Brasil - Marco Polo de Mello Lopes e Sergio Leite de Andrade (MAIA, 2018); e FIRJAN (Federação das Indústria do RJ) - Cristiano Buarque Franco Neto (EM REUNIÃO..., 2018).

Com relação à coação - prática autoritária e de repressão que ocorre quando donos de empresas ou superiores tentam influenciar os votos ou direcionar nas escolhas de seus subordinados, valendo-se da posição hierárquica de poder -, a revista online Publica apontou que a Procuradoria-Geral do Trabalho (PGT) havia registrado, até o dia 19 de outubro de 2018, 199 denúncias contra mais de 60 empresas pelo país, em 14 estados, relacionadas à coação eleitoral. A revista apontou as seguintes empresas: Komeco, Havan, Grupo K1, Tabacos D’Itália, Rede Condor, Sierra Móveis, SESC, SENAC, Construtora Mânica (MACIEL e BARROS, 2018). O jornal O Globo ainda apontou a empresa Sofá e Complementos (DUTRA, MARTINS e COSTA, 2018).

Essas coaçôes, que estavam na contramão do modelo constitucional de democracia, se davam em conversas reservadas ou em reuniōes com trabalhadores, quando os empresários faziam campanhas afirmando que o candidato Bolsonaro iria melhorar a economia do país e, consequentemente, a situação para os empresários. Caso o político não ganhasse, os empresários ameaçavam explicitamente dispensar funcionários. Luciano Hang declarou na sua página do Facebook: "Pessoal, nós vamos sofrer muito porque nos dói no coração ter que fechar empresas, ter que demitir pessoas. [...] Não se esqueça: quando um país fica pobre, tudo desvaloriza" (MACIEL e BARROS, 2018).

Na Komeco, aponta a Publica, Denisson Moura de Freitas, proprietário da empresa, gravou um áudio em que dizia:

Semana que vem, pessoal, é uma semana que aqui na empresa nós estamos chamando de semana do Bolsonaro. Todo funcionário que quiser colocar um adesivo [do candidato] a empresa vai pagar metade do adesivo. A camiseta [do candidato] custa 30 pila, nós vamos estar comprando por 30 e vendendo para o funcionário para ele poder pagar $R \$ 10$. Vai ser a semana que a gente vai trabalhar a semana inteira 
uniformizado de Bolsonaro: carro adesivado e camiseta vestida (MACIEL e BARROS, 2018).

Conforme o site do Ministério Público do Trabalho (MPT), as seguintes empresas foram intimadas e punidas: Flapa Minerações e Incorporações, Rede Condor (PRESIDENTE..., 2018), CNC, Grupo AB Abolição, Grupo Havan, MS Caran Gomes Serviços de Estética Eireli, LF Com. de Alimentos, Transterra Terraplanagem, Supermassa e Artefatos de Cimento, Fibroplast, Frigorífico Naturafrig, Castagna Krum Iluminação, Construtora Mânica JJR e Tabacos D'Itália ${ }^{20}$.

Conforme se observa, as articulaçóes empresariais em torno de Bolsonaro começaram pelo varejo, mas, na reta final das eleiçóes, setores de capital da indústria se aproximaram do candidato da extrema-direita após ficar visível a inviabilidade política e eleitoral de Henrique Meirelles (MSB) e Geraldo Alckmin (PSDB), os dois, inicialmente, preferidos da alta burguesia brasileira.

A seis dias do segundo turno das eleiçôes, Bolsonaro recebeu representantes de setor da indústria: máquinas e equipamentos, produtos químicos, setor têxtil, construção, aço e comércio exterior. $\mathrm{Na}$ ocasião, os representantes entregaram documento para o capitão em que afirmavam que a violência e o desemprego não podiam ser enfrentados sem o crescimento sustentável da economia e equilíbrio das contas públicas. Fizeram também uma série de pedidos para o setor produtivo, tais como redução dos impostos e dos juros (BOLSONARO...,2018c).

\section{Movimento Brasil 200}

Em janeiro de 2018, foi criado o Movimento Brasil 20021, encabeçado pelo empresário Flávio Rocha (Riachuelo), uma organização que aglomera empresários de vários segmentos e que, inicialmente, apoiou a candidatura de Rocha. Após a desistência do empresário de disputar a presidência, este passou a apoiar Bolsonaro rumo à Brasília. Conforme Fontes, o Estado é uma área privilegiada de atuação e mediação dos múltiplos interesses das frações de classes burguesas por meio de associaçóes e entidades que penetram no aparelho de Estado, consolidando e

\footnotetext{
${ }^{20}$ As informaçóes deste parágrafo foram retiradas do Portal do Ministério Público do Trabalho em publicações de 2018. Os endereços específicos, no entanto, não se encontram mais no ar.

${ }^{21}$ Movimento Brasil 200 é uma referência ao bicentenário da Independência brasileira em 2022 (BRASIL 200..., 2019).
} 
ampliando para fora dos seus limites estreitos de classe sua capacidade de intervenção na política nacional (FONTES, 2005).

$\mathrm{Na}$ sua fundação, o Movimento Brasil assinou uma carta-manifesto convocando os empresários brasileiros a assumirem o protagonismo político e econômico do Brasil. Assinaram: Luiza Helena Trajano (Magazine Luiza), Walter Torre (WTorre) 22, Roberto Justus e João Apolinário (Polishop), Luciano Hang (Havan), Antônio Carlos Pipponzi (Raia Drogasil), Carlos Tilkian (Estrela), Nadir Moreno (UPS), Sônia Hess e Sebastião Bomfim (Centauro), Alberto Saraiva (Habib's), Edgard Corona (Bio Ritmo/Smart Fit) e Marcos Gouvêa de Souza (Grupo GS\&Gouvêa de Souza) (GRUPO..., 2018).

Segundo o seu site oficial, “[...] o Brasil 200 é composto de gente que resolveu tomar o lado do Brasil e não se omitir da construção de uma agenda política que ponha a nação em primeiro lugar" (MOVIMENTO BRASIL 200, 2018a).

Quadro 2-Membros do Movimento Brasil 200

\begin{tabular}{|l|l|}
\hline \multicolumn{1}{|c|}{ EMPRESÁRIOS } & \multicolumn{1}{c|}{ EMPRESAS } \\
\hline Antonio Alberto Saraiva & $\begin{array}{l}\text { Habib's - presidente rede Ragazzo, da Arabian Bread, } \\
\text { da Ice Lips, da Promilat, da Vox Line }\end{array}$ \\
\hline JR Diesel \\
\hline Sonaldo Rufino & Dudalina \\
\hline Luciano Hang & Havan \\
\hline Flávio Rocha & Riachuelo \\
\hline Edgard Corona & Grupo Bio Ritmo/Smart Fit \\
\hline Sebastião Bomfim & $\begin{array}{l}\text { Grupo SBF: Centauro, ByTenis e Almax Sports e } \\
\text { operador das lojas Nike Store no Brasil }\end{array}$ \\
\hline Roberto Justus & $\begin{array}{l}\text { Newcomm: Y\&R, Grey Brasil, Wunderman, VML e } \\
\text { RedFuse, Ação Premedia e Tecnologia }\end{array}$ \\
\hline João Apolinário & Polishop \\
\hline Marcelo Monteiro & $\begin{array}{l}\text { Procurador de Justiça (MPRJ). Professor concursado da } \\
\text { UERJ. }\end{array}$ \\
\hline José Victor Oliva & $\begin{array}{l}\text { Holding Clube: Banco de Eventos, Rio360, Samba.pro, } \\
\text { Lynx, Cross Networking, The Aubergine }\end{array}$ \\
\hline Giuliano Donini & Marisol \\
\hline Marcelo H. Ribeiro Alecrim & Ale Combustível \\
\hline Roberto Motta & Consultor segurança pública \\
\hline
\end{tabular}

${ }^{22}$ Em 2016 foi alvo da Lava Jato, suspeito de ter recebido R \$ 18 milhóes de um consórcio concorrente para desistir da licitação da obra da Cenpes (Centro de Pesquisas da Petrobrás) (NUNES e CARAZZAI, 2016). 


\begin{tabular}{|l|l|}
\hline Ericsson Henrique Luef & Companhia Hemmer Indústria e Comércio \\
\hline Pedro Thompson & Estácio \\
\hline Ronaldo Pereira Júnior & Óticas Carol \\
\hline Renato Feder & Multilaser \\
\hline Alexis Fontayne & SOLEPOXY Ind. e Com. de Resinas \\
\hline Cleber Moraes & $\begin{array}{l}\text { Ex-presidente da Bematech e atual presidente da } \\
\text { Schneider Eletric }\end{array}$ \\
\hline Fábio Colletti Barbosa & $\begin{array}{l}\text { Grupo Santander Brasil, a Federação Brasileira dos } \\
\text { Bancos (Febraban), Grupo Abril }\end{array}$ \\
\hline
\end{tabular}

Fonte: Movimento Brasil 200 (2018a) e Conheça... (2018).

Esse movimento tem como meta a defesa de agenda liberal para a economia e da agenda conservadora no campo social (MOVIMENTO BRASIL 200, 2018a). Seus princípios são: menos Estado, empreendedores e colaboradores não são inimigos, e escola sem partido e sem erotização precoce, respeitando o senso comum e as famílias (MOVIMENTO BRASIL 200, 2018b).

Em 6 de junho de 2018, o Brasil 200 criou a Frente Parlamentar Mista Brasil 200, no saláo nobre da Câmara dos Deputados, para influenciar a pauta no Congresso. O grupo contava, em novembro do mesmo ano, com 249 deputados e 20 senadores, além de empresários, acadêmicos e membros da sociedade civil simpáticos ao movimento (MOVIMENTO BRASIL 200, 2018c). Na Câmara, o colegiado era coordenado pelo deputado Jerônimo Goergen (PP-RS), e no Senado Federal, o grupo ficou sob o comando do senador Eduardo Lopes (PRB-RJ) (FRENTE PARLAMENTAR BRASIL 200..., 2018).

A carta de princípios da Frente Parlamentar previa a redução do custo da máquina pública; o combate à corrupção e ao excesso de regulamentação governamental; o estímulo à competitividade; o fim de privilégios ou proteçôes; e a diminuição da carga tributária. A Frente podia utilizar o espaço da Câmara, desde que suas atividades náo interferissem no andamento dos outros trabalhos da Casa, não implicassem contratação de pessoal nem no fornecimento de passagens aéreas. Para fins de registro, ela deveria ser integrada por, no mínimo, um terço de membros do Poder Legislativo federal (FRENTE PARLAMENTAR..., 2018).

Em julho, o coordenador da frente parlamentar propôs criara "CPI do Facebook", que consistia em combater a retirada do ar de páginas e contas ligadas aos coordenadores do Movimento Brasil Livre (MBL), como parte da política de combate a notícias falsas. A CPI entendia como arbitrária a decisão de desativar contas falsas que emitiam fake news (COORDENADOR..., 2018). Tal posição de 
combate foi bastante coerente, uma vez que o candidato cresceu nas pesquisas e ganhou com a ajuda de notícias falsas.

No ano seguinte, a frente parlamentar apoiou a aprovação da Reforma da Previdência. Segundo Flávio Gurgel Rocha, “[...] nós estamos às vésperas de um desafio ainda maior do que uma eleição presidencial". Acrescentou, "[...] precisamos nos unir, todos aqueles que defendem o mesmo propósito, e os propósitos são três: reforma da Previdência, reforma da Previdência e reforma da Previdência” (BRASIL 200...,2019).

O Movimento Brasil 200 tornou-se Instituto Brasil 200, dirigido por Gabriel Kanner, sobrinho de Flávio Rocha. Por meio da entidade, o grupo de empresários faz lobby no Executivo e no Legislativo por políticas liberais. O instituto agora pode abrir filiais, criar instituiçóes, conselhos etc., o que o permite se instalar pelo país para ampliar suas ações ${ }^{23}$.

\section{Apoio financeiro à candidatos políticos}

O envolvimento do empresariado nas eleições de 2018 não se limitou a financiar e apoiar Bolsonaro, foram ampliadas as doaçôes para candidatos à Câmara de diferentes partidos políticos. A seguir, lista-se apenas os que conseguiram se eleger.

Quadro 3 - Empresários e candidatos financiados e eleitos

\begin{tabular}{|c|c|}
\hline EMPRESÁRIOS & CANDIDATOS \\
\hline Abílio Diniz & $\begin{array}{l}\text { Frederico Braun D’Avila (PSL) } \\
\text { Daniel J. da Silva Oliveira } \\
\text { Vinicius Lazzer Poit (NOVO) } \\
\text { Ricardo Luis Mellao (NOVO) } \\
\text { Fábio Maia Ostermann (PSL) } \\
\text { Marcelo Calero Faria Garcia (PPS) } \\
\text { Luiz Eduardo Carneiro da Silva Souza (PSL) } \\
\text { João Agripino da Costa Dora Junior (PSDB) }\end{array}$ \\
\hline Afrânio Barreira Filho & $\begin{array}{l}\text { Beatriz KicisTorrents de Sordi (PRP) } \\
\text { Jair Messias Bolsonaro (PSL) }\end{array}$ \\
\hline Flávio Gurgel Rocha & $\begin{array}{l}\text { Damaris Dias Moura Kuo (PHS) } \\
\text { Carla Zambelli Salgado (PSL) }\end{array}$ \\
\hline Luciano Hang & Carlos Roberto Massa Junior (PSD) \\
\hline Meyer Joseph Nigri & $\begin{array}{l}\text { Henri Ozi Cukier (NOVO) } \\
\text { Milton Leite da Silva Filho (DEM) } \\
\text { João Agripino da Costa Doria Jr. (PSDB) }\end{array}$ \\
\hline
\end{tabular}

${ }^{23} \mathrm{O}$ atual site do Instituto Brasil 200 não disponibiliza os nomes dos membros. 


\begin{tabular}{|c|c|}
\hline Rubens Ometto Silveira Mello & $\begin{array}{l}\text { Mara Cristina Gabrilli (PSDB) } \\
\text { Luiz Carlos Heinze (PP) } \\
\text { Carlos Roberto Massa Jr. (PSD) } \\
\text { Hugo Leal Melo da Silva (PSB) } \\
\text { João Agripino da Costa Doria Jr. (PSDB) } \\
\text { Felix de Almeida Mendonça Jr. (PDT) } \\
\text { Ricardo José Magalhães Barros (PP) } \\
\text { Manuel Barbosa do Nascimento } \\
\text { Fernando Monteiro de Albuquerque (PP) } \\
\text { Roberto Turchi de Morais (REDE) } \\
\text { João Antônio Heinzen Amin Helou (PP) } \\
\text { Carlos Alberto Rolim Zarattini (PT) } \\
\text { Tereza Cristina Correa da Costa Dias (DEM) } \\
\text { Ronaldo Caiado (DEM) } \\
\text { Jerônimo Pizzolotto Goergen (PP) } \\
\text { Efraim de Araujo Morais Filho (DEM) } \\
\text { Edmir José Abri Chedid (DEM) } \\
\text { Fernando Bezerra de Souza Coelho Fo (PSB) } \\
\text { Arlindo Chignalia Jr. (PT) } \\
\text { Sergio de Souza (MDB) } \\
\text { Vinicius Almeida Camarinha (PSB) } \\
\text { Eugenio José Zuliani (DEM) } \\
\text { Pedro DeboniLupion Mello (DEM) } \\
\text { Reinaldo de Souza Alguz (PV) } \\
\text { Onyx Dornelles Lorenzoni (DEM) } \\
\text { Arnaldo Calil Pereira Jardim (PPS) }\end{array}$ \\
\hline José Salim Mattar & $\begin{array}{l}\text { Tiago Lima Mitraud de Castro Leite (NOVO) } \\
\text { Pedro Oliveira Cunha Lima (PSDB) } \\
\text { Marcel Van Hattem (NOVO) } \\
\text { Kim PatrocaKataguiri (DEM) } \\
\text { Arthur Moledo do Val (DEM) } \\
\text { Onyx Dornelles Lorenzoni (DEM) } \\
\text { Rodrigo Felinto Ibarra Epitacio Maia (DEM) } \\
\text { Bruno André de Souza (PSB) } \\
\text { Lucas de Vasconcelos Gonzales (NOVO) }\end{array}$ \\
\hline Sebastião Vicente Bomfim Fo & $\begin{array}{l}\text { Daniel J. da Silva Oliveira } \\
\text { Kim PatrocaKataguiri (DEM) } \\
\text { João Agripino da Costa Doria Jr. (PSDB) } \\
\text { Carla Zambelli Salgado (PSL) } \\
\text { Arthur Moledo do Val (DEM) } \\
\text { Joice Cristina Hasselmann (PSL) }\end{array}$ \\
\hline Marcelo Henrique Ribeiro Alecrim & Antônio de Morais Andrade Neto (PSDB) \\
\hline
\end{tabular}


Elaine de Almeida Bortone

\begin{tabular}{|l|l|}
\hline & João da Silva Maia (PR) \\
\hline Luiza Helena Trajano Rodrigues & Marina Medeiros Helou (REDE) \\
\hline Edgar Gomes Corona & Carla Zambelli Salgado (PSL) \\
\hline
\end{tabular}

Fonte: Adaptado de TSE (2018).

Conforme o quadro, Rubens Ometto Silveira Mello foi o maior doador da eleição, elegendo 26 candidatos dos 53 para quem doou R $\$ 7$ milhóes (portanto, $45 \%$ foram eleitos) (CAESAR, 2018). Vale salientar que o empresário, desde 2017, vinha apoiando também o candidato Geraldo Alckmin (PSDB), ao qual elogiou e afirmou que tinha qualidades para assumir (SCARAMUZZO e SCHELLER, 2018). Em 2018, Mello ofereceu um jantar em sua residência para empresários em torno do candidato tucano, quando reafirmaram seu apoio (RACY e SCARAMUZZO, 2018).

Rubens explicou que escolheu para apoiar os candidatos que se posicionaram a favor da "livre iniciativa". Um dos seus critérios foi doar para candidatos ligados ao espectro político da direita e que fossem a favor das reformas previdenciária, política e tributária, fatores que diziam respeito aos seus interesses. Um dos premiados com a doação foi Onyx Lorenzoni (DEM-RS), que recebeu R\$ 200 mil (CAESER, 2018).

O segundo colocado nas doações foi José Salim Mattar (Localiza), que foi um dos fundadores do Instituto Millenium e do Instituto de Formação de Líderes. Em 2016, Mattar foi um dos empresários que encabeçou o movimento "Você Muda o Brasil", ao lado de Luiza Helena Trajano (Magazine Luiza), Jefferson de Paula (Arcelor Mittal), Paulo Kakinoff (Gol), Pedro Passos (Natura), Pedro Wongtschowski (Ultra), Rubens Menin (MRV) e Walter Schalka (Suzano). O movimento debatia temas como ética, civismo, educação e desenvolvimento. Em 2018, organizaram um encontro para discutir o engajamento da sociedade civil na esfera política. Mattar integrou também o Conselho Superior da Associação Comercial do Paraná no mandato de 2017 a 2019 (MACIEL, 2019a).

Nas eleições de 2018, Mattar fez as seguintes doações para partidos políticos: R\$ 2,9 milhões para 30 candidaturas dos partidos: Novo ( $\mathrm{R} \$ 1,4$ milhão), DEM ( $\$$ \$ 650 mil), PSDB (R\$ $500 \mathrm{mil})$, PSB (R\$ $100 \mathrm{mil}), \mathrm{DC}(\mathrm{R} \$ 50 \mathrm{mil}), \mathrm{PTB}$ (R\$ $50 \mathrm{mil})$, PSC (R\$ 50 mil), PHS (R\$ 25 mil) e PSL (R\$ 20 mil) (MACIEL, 2019b).

Mattar elegeu nove candidatos e foi o terceiro maior financiador de Lorenzoni, que recebeu um total de $\mathrm{R} \$ 663$ mil de doadores individuais, dos quais $\mathrm{R} \$ 100$ mil foram repassados pelo dono da Localiza. Ainda, foram contemplados os seguintes candidatos que não foram eleitos: Ricardo Salles (Novo-SP) e os relatores da reforma 
trabalhista na Câmara, Rogério Marinho (PSDB-RN), e no Senado, Ricardo Ferraço (PSDB) (FERNANDES, 2019).

A relação de Mattar com a política partidária e as vultosas doações já vem de algum tempo. A Localiza doou R $\$ 315$ mil à primeira campanha de Aécio ao governo de Minas Gerais, em 2002. Para retribuir o apoio recebido, o então governador reduziu a alíquota do IPVA, igualando-a à do Paraná. Mattar passou a emplacar os carros em Minas, gerando receita aos cofres estaduais. Em 2014, o empresário doou $\mathrm{R}$ \$ 1,5 milhão para a direção nacional do PSDB e R \$ 45 mil para a do DEM. Outros R\$ 205 mil foram destinados a quatro candidatos do DEM, PP e PSDB (MACIEL, 2019b).

Em seguida, vem Abílio Diniz, que elegeu oito candidatos. Abílio é presidente do Conselho de Administração da Península Participações e membro dos Conselhos de Administração do Carrefour Global e do Carrefour Brasil. Além disso, é professor da FGV, onde ministra aulas no curso "Liderança 360" (DINIZ, c2018). Em dezembro de 2017, o Carrefour retaliou, perseguiu e demitiu trabalhadores que entraram em greve contra as medidas da reforma trabalhista de Temer, aplicadas pela empresa. Eles reivindicavam manutenção do pagamento de adicional de $100 \%$ sobre as horas trabalhadas nos feriados e domingos, folgas adicionais pelo trabalho nos feriados; fim do desvio de função; intervalo de 15 minutos para lanche; e fim do assédio moral (TRABALHADORES..., 2017).

\section{Conclusões}

Conforme discutido, o empresariado aloca grandes recursos em políticos de maneira estratégica, com o objetivo de conquistar influência política dentro do parlamento para, assim, ser favorecido com políticas públicas que beneficiem seu negócio. Um caso emblemático foio do deputado Rogério Simonetti Marinho (PSDB-RN), relator da Reforma Trabalhista na Câmara, que, em 2017, recebeu R\$ 244 mil de grandes empresários para sua campanha à reeleição. $\mathrm{O}$ valor representou $42 \%$ do total de receitas da campanha. A principal doação foi de Nevaldo Rocha (Riachuelo), no valor de R 100 mil. Empresários da Localiza, Centauro, Raia Drogasil, Polishop e Habib's também doaram para o político (HIRABAHASI, 2018).

A reforma trabalhista foi muito esperada pelos empresários, pois promoveu o corte de uma série de direitos do trabalhador, o que, consequentemente, aumentou seus lucros. Marinho ainda votou a favor da admissibilidade do processo de impeachment de Dilma Rousseff. Durante ogoverno Temer, votou a favor 
da PEC do Teto dos Gastos Públicos e votou contra o processo em que se pedia abertura de investigaçáo do presidente, ajudando a arquivar a denúncia do Ministério Público Federal.

Nas eleições de 2018, Marinho não conseguiu ser reeleito, mas foi anunciado como secretário especial da Previdência Social no governo Bolsonaro, mesmo sendo acusado por corrupção.

Conforme analisado no artigo, os empresários, ao apoiarem candidatos políticos, buscavam vantagens e posições importantes no Estado, de onde trabalhavam para beneficiar os negócios de sua classe. Bolsonaro, que afirmou que "Está na hora de o Brasil ter empresários cuidando das coisas" (MORAIS, 2018), alocou empresários que o apoiaram e o financiaram.

José Salim Mattar ficou responsável pelas privatizações na Secretaria Especial de Desestatização e Desinvestimento do Ministério da Economia. Mattar passou a ter a função de tirar do Estado tudo aquilo que pode ir para a iniciativa privada. Tereza Cristina, presidente da Frente Parlamentar da Agropecuária (FPA), que havia apoiado Bolsonaro, tornou-se Ministra da Agricultura. Ricardo Salles (Novo-SP), financiado por Mattar, assumiu o ministério do Meio Ambiente.

Bolsonaro deu início à execução das promessas de campanha, as quais atenderiam aos interesses do empresariado, que o apoiou e o ajudou a subir ao poder. Tais promessas foram: a mudança das leis trabalhistas, a aprovação da Reforma da Previdência, o corte nos gastos públicos, a remoção da função da FUNAI nas demarcações de terras, a neutralização do IBAMA, extinção das estatais etc.

Foi aprovada a proposta da Reforma da Previdência, que acabou com vários direitos da classe trabalhadora. Para aprofundar a Reforma Trabalhista de Temer, Bolsonaro sancionou a "minirreforma trabalhista", que alterou e flexibilizou várias regras trabalhistas, o que colocou o trabalhador em uma situação ainda mais difícil e beneficiou o empresariado. Para atender ao empresário do agronegócio, o governo liberou o uso de diversos agrotóxicos, alguns proibidos nos seus países de origem e condenados pela Agência Nacional de Vigilância Sanitária (ANVISA), pois causam danos irreversíveis aos consumidores.

Com relação aos gastos públicos, o governo fez cortes na Educação e extinguiu bolsas de estudos e pesquisa, colocando em risco as pesquisas do país; o salário mínimo não teve o ganho real, apenas a reposição da inflação; o Secretário de Privatizaçóes, o empresário Mattar, passou a cuidar do processo que poderá colocar fim ao conglomerado estatal de TV, rádio e agência de notícias, a Empresa Brasil de Comunicação (EBC). Ainda, Bolsonaro tentou transferir para o Ministério da 
Agricultura a atribuição de realizar as demarcações de terras indígenas, tirando a função da FUNAI.

Por fim, com relação ao IBAMA, o presidente vem tentando neutralizar o papel da estatal na aplicação de multas ambientais, crimes ambientais causados por empresários da mineração, agronegócio, madeireiras etc.

\section{- Elaine de Almeida Bortone é Doutora em História Social pela Universidade Federal do Rio de Janeiro (UFRJ). Mediadora à distância - UNIRIO. E-mail: elainebortone@gmail.com.br.}

\section{Referências}

BECKER, Fernanda; OLIVEIRA, Regiane. Luciano Hang e o pelotão de empresários "anticomunistas" pró-Bolsonaro. El País, 02 set. 2018. Disponível em: <https://brasil.elpais.com/brasil/2018/08/21/politica/1534888407_697144.html>. Acesso em: 29 mar. 2019.

BOLSONARO pede apoio a nomes de peso do PIB nas eleiçóes 2018. Estadão, 04 jul. 2018a. Disponível em: <https://politica.estadao.com.br/noticias/eleicoes, bolsonaro-pede-apoio-a-nomes-depeso-do-pib-nas-eleicoes-2018,70002385201 >. Acesso em: 29 mar. 2019.

BOLSONARO se apresenta como alternativa ética da eleição presidencial. Voto, 30 ago. 2018b. Disponível em: <http://www.revistavoto.com.br/bolsonaro-se-apresenta-como-alternativa-etica-daeleicao-presidencial/>. Acesso em: 29 mar. 2019.

BOLSONARO recebe representantes de setores da indústria e diz que investirá em saneamento se eleito. G1, 22 out. 2018c. Disponível em: <https:/g1.globo.com/politica/eleicoes/2018/ noticia/2018/10/22/bolsonaro-recebe-representantes-de-setores-da-industria-e-diz-que-investira-emsaneamento-se-eleito.ghtml>. Acesso em: 27 mar. 2019.

BORTONE, Elaine de Almeida. O Instituto de Pesquisas e Estudos Sociais (IPES) e a ditadura empresarial-militar: os casos das empresas estatais federais e da indústria farmacêutica (1964-1967). 2018. Tese (Doutorado em História) - Programa de Pós-Graduação em História, Universidade Federal do Rio de Janeiro, Rio de Janeiro, 2018.

BRASIL 200 cria Frente Parlamentar e apoia reforma da Previdência. Boletim da Liberdade, 27 mar. 2019. Disponível em: <https://www.boletimdaliberdade.com.br/2019/03/27/movimento-brasil-200cria-frente-parlamentar-e-apoia-a-reforma-da-previdencia/>. Acesso em: 30 mar. 2019.

CAESAR, Gabriela. Maior doador desta eleição ajuda a eleger 24 candidatos de 10 partidos diferentes. G1, 12 out. 2018. Disponível em: <https://g1.globo.com/politica/eleicoes/2018/eleicao-em- 
numeros/noticia/2018/10/12/maior-doador-desta-eleicao-ajuda-a-eleger-24-candidatos-de-10partidos-diferentes.ghtml>. Acesso em: 29 mar. 2019.

CARDOSO, Fernando Henrique. Empresário industrial e desenvolvimento econômico no Brasil. São Paulo: Difusão Europeia do Livro, 1972.

CONHEÇA os primeiros apoiadores do Manifesto Brasil 200. Portal no Ar, 21 jan. 2018. Disponível em: <http://portalnoar.com.br/conheca-os-primeiros-apoiadores-do-manifesto-brasil-200/>. Acesso em: 30 mar. 2019.

COORDENADOR da Frente Parlamentar Mista Brasil 200 propõe criar "CPI do Facebook". Isto é, 25 jul. 2018. Disponível em: <https://istoe.com.br/coordenador-da-frente-parlamentar-mista-brasil200-propoe-criar-cpi-do-facebook/>. Acesso em: 30 mar. 2019.

COTIAS, Adriana. Carta do Itaú a investidores provoca reação na web e banco se explica. Seu Crédito Digital, 30 out. 2018. Disponível em: <https://seucreditodigital.com.br/itau-e-criticado-apoio-abolsonaro/. Acesso em: 29 mar. 2019.

DESIDÉRIO, Mariana. Os empresários que apoiam candidatura de Bolsonaro. Exame, 27 set. 2018. Disponível em: <https://exame.abril.com.br/negocios/os-empresarios-que-apoiam-bolsonaro/>. Acesso em: 28 mar. 2019.

DINIZ, Abilio. Biografia. c2018. Disponível em: <http://abiliodiniz.com.br/biografia/>. Acesso em: 30 mar. 2019.

DINIZ, Eli. Empresariado, regime autoritário e modernização capitalista: 1964-1985. In: SOARES, Glaucio Ary Dillon; D'ARAÚJO, Maria Celina. 21 anos de regime militar. Balanços e perspectivas. Rio de Janeiro: FGV, 1994.

DUTRA, Bruno; MARTINS, Gabriel; COSTA, Daiane. Denúncias de coação eleitoral em empresas já passam de 120 em todo o país. O Globo, 10 jul. 2018. Disponível: <https://oglobo.globo.com/ economia/denuncias-de-coacao-eleitoral-em-empresas-ja-passam-de-120-em-todo-pais-23127729>.

Acesso: 28 mar.2019.

EM REUNIÃO com representantes de entidades empresariais, Bolsonaro cita medidas de Trump, como exemplo. Gaúcha ZH, 22 out. 2018. Disponível em: <https://gauchazh.clicrbs.com.br/politica/eleicoes/noticia/2018/10/em-reuniao-com-representantesde-entidades-empresariais-bolsonaro-cita-medidas-de-trump-como-exemplocjnkyfpv507ax01 piq2xmdbl9.html>. Acesso: 30 mar. 2019.

FERNANDES, Leonardo. Responsável por privatizaçóes, Salim Mattar "investiu" quase R\$ 3 milhóes na eleiçấo. Sul 21, 09 jan. 2019. Disponível em: <https://www.sul21.com.br/ultimasnoticias/politica/2019/01/responsavel-por-privatizacoes-salim-mattar-investiu-quase-rdollar-3milhoes-na-eleicao/>. Acesso em: 28 mar. 2019.

FIORATTI, Gustavo. Record amplia visibilidade de Bolsonaro e evita críticas ao presidenciável. Folha de S. Paulo, 24 out. 2018. Disponível em: <https://www1.folha.uol.com.br/poder/2018/10/recordamplia-visibilidade-de-bolsonaro-e-evita-criticas-ao-presidenciavel.shtml>. Acesso: 29 mar. 2019.

FONTES, Virgínia. Reflexôes im-pertinentes. História e capitalismo contemporâneo. Rio de Janeiro: Bom Texto, 2005.

FRENTE PARLAMENTAR BRASIL 200 é lançada no Congresso Nacional. Republicanos 10, 06 jun. 2018. Disponível em: <https://www.prb10.org.br/noticias/prb-nacional/frente-parlamentarbrasil-200-e-lancada-no-congresso-nacional/>. Acesso em: 30 mar. 2019. 
FRENTE PARLAMENTAR vai debater propostas de reestruturação do Estado brasileiro. Portal da Câmara dos Deputados, 5 jun. 2018. Disponível em: <http://www2.camara.leg.br/camaranoticias/noticias/POLITICA/558494-FRENTEPARLAMENTAR-VAI-DEBATER-PROPOSTAS-DE-REESTRUTURACAO-DO-ESTADOBRASILEIRO.html>. Acesso: 30 mar. 2019.

GARCIA, Taciana. Bolsonaro monta time de empresários milionários para atacar os trabalhadores. Esquerda Diário, 09 out. 2018. Disponível em: <http://www.esquerdadiario.com.br/Bolsonaromonta-time-de-empresarios-milionarios-para-atacar-os-trabalhadores>. Acesso em: 29 mar. 2019.

GIELOW, Igor. Bolsonaro encontra empresários e cita Rocha como ministro. Folha de S. Paulo, 12 ago. 2018. Disponível em: <https://www1.folha.uol.com.br/poder/2018/08/bolsonaro-faz-ofensivapara-atrair-o-pib-em-sao-paulo.shtml>. Acesso em: 28 mar. 2019.

GRAMSCI, Antônio. Cadernos do Cárcere. Rio de Janeiro: Civilização Brasileira, 2014. v. 2.

GRILlO, Marco; MENEZES, Maiá; PRADO, Thiago. Exclusivo: "Não entendo mesmo de economia", afirma Bolsonaro. $O$ Globo, 21 jul. 2018. Disponível em: $<$ https://oglobo.globo.com/brasil/exclusivo-nao-entendo-mesmo-de-economia-afirma-jair-bolsonaro22908268>. Acesso em: 28 mar. 2019.

GRUPO de empresários convoca elite brasileira a assumir protagonismo político. Época, 18 jan. 2018. Disponível em: <https:/epocanegocios.globo.com/Brasil/noticia/2018/01/grupo-de-empresariosconvoca-elite-brasileira-assumir-protagonismo-politico.html>. Acesso em: 30 mar. 2019.

HIRABAHASI, Gabriel. Grandes empresários financiam a campanha do relator da reforma trabalhista. Época, 1 set. 2018. Disponível em: <https:/epoca.globo.com/expresso/grandesempresarios-financiam-campanha-do-relator-da-reforma-trabalhista-23028617>. Acesso em: 30 mar. 2019.

LESSA, Ricardo. Dois empresários paulistas contam por que estimulam Bolsonaro. Folha de S. Paulo, 19 fev. 2018. Disponível em: <https://piaui.folha.uol.com.br/dois-empresarios-paulistas-contampor-que-estimulam-bolsonaro>. Acesso em: 29 mar. 2019.

LOJAS Americanas vendem camisetas pró-Bolsonaro e anti-Lula. Exame, 30 ago. 2018. Disponível em: <https:/exame.abril.com.br/negocios/lojas-americanas-vendem-camisetas-pro-bolsonaro-e-antilula/>. Acesso em: 30 mar. 2019.

MACIEL, Alice. Da Localiza à Esplanada: Salim Matar é o raio privatizador de Bolsonaro. Exame, 12 maio 2019a. Disponível em: <https:/exame.abril.com.br/economia/o-raio-privatizador-debolsonaro/>. Acesso em: 29 maio 2019.

MACIEL, Alice. O raio privatizador de Bolsonaro. A Pública, 9 mai. 2019b. Disponível em: $<$ https://apublica.org/2019/05/o-raio-privatizador-de-bolsonaro/>. Acesso em: 9 maio 2019.

MACIEL, Ana; BARROS, Ciro. Maioria das denúncias de coação eleitoral é pró-Bolsonaro. $A$ Pública, 10 out. 2018. Disponível em: <https://apublica.org/2018/10/maioria-das-denuncias-decoacao-eleitoral-e-pro-bolsonaro/?fbclid=IwAR1gg62QaQrhi1JpsQQ1ASCcGsbsPjItH6Yo5m8GopzKwFU6oZuSjJG5eA>. Acesso em: 29 mar. 2019.

MAIA, Gustavo. Bolsonaro recebe apoio de industriais e diz que não quer atrapalhá-los. UOL, 11 out. 2018. Disponível em: <https://noticias.uol.com.br/politica/eleicoes/2018/noticias/2018/10/22/bolso naro-recebe-apoio-de-industriais-e-diz-que-nao-querer-atrapalha-los.htm>. Acesso em: 29 mar. 2019. 
MANCUSO, Wagner Pralon. O lobby da indústria no Congresso Nacional: empresariado e política no Brasil contemporâneo. Dados - Revista de Ciências Sociais, v. 47, n. 3, p. 505-547, 2004.

MASCARENHAS, Gabriel. Empresa de Onyx Lorenzoni deve quase 1 milhão à União. O Globo, 05 jun. 2019. Disponível em: <https://blogs.oglobo.globo.com/lauro-jardim/post/empresa-de-onyxlorenzoni-deve-quase-r-1-milhao-uniao.html>. Acesso em: 30 mar. 2019.

MATSUI, Naomi. Confederação de associações comerciais declara apoio à Bolsonaro. Poder 360, 03 out 2018. Disponível: <https://www.poder360.com.br/eleicoes/confederacao-de-associacoescomerciais-declara-apoio-a-bolsonaro/>. Acesso: 30 mar. 2019.

MORAIS, Tarcisio. Empresários surpresos após Bolsonaro rejeitar doaçóes financeiras. Renova Mídia, 13 ago. 2018. Disponível em: <https://renovamidia.com.br/empresarios-surpresos-apos-bolsonarorejeitar-doacoes-financeiras/>. Acesso em: 30 mar. 2019.

MOVIMENTO BRASIL 200. Quem somos. 2018a. Disponível em: <https://www.brasil200.com.br/ quem-somos 21.10.18>. Acesso em: 30 mar. 2019.

MOVIMENTO BRASIL 200. Propostas. 2018b. Disponível em: <https://www.brasil200.com.br/ propostas $>$. Acesso em: 30 mar. 2019.

MOVIMENTO BRASIL 200. Frente Parlamentar Brasil 200. 2018c. Disponível em: <https://www.brasil200.com.br/single-post/2018/06/05/Frente-Parlamentar-Brasil-200-\%C3\%A9lan\%C3\%A7ada-no-Congresso-Nacional>. Acesso em: 30 mar. 2019.

NUNES, Walter; CARAZZAI, Estelita Hass. Dono da WTorre é alvo da Lava Jato, mas não é encontrado. Folha de S. Paulo, 4 jul. 2016. Disponível em: <https:/www1.folha.uol.com.br/ poder/2016/07/1788468-dono-da-wtorre-e-alvo-da-lava-jato-mas-nao-e-encontrado.shtml>. Acesso em: 27 mar. 2019.

NUNES, Wálter; FIORATTI, Gustavo. Dono da Havan cresceu sob governos petistas e acumula processos. Folha de S. Paulo, 26 out. 2018. Disponível em: <https:/www1.folha.uol.com.br/ poder/2018/10/dono-da-havan-cresceu-sob-governos-petistas-e-acumula-processos.shtml>. Acesso em: 28 mar. 2019.

OLIVEIRA, Regiane. O bilionário "socialista" que apoia Bolsonaro. El País, 23 jul. 2019. Disponível em: <https://brasil.elpais.com/brasil/2019/07/12/politica/1562960378_814880.html>. Acesso em: 24 nov. 2019.

PABLITO, Marcello. Conheça alguns dos homens mais ricos do país e por que eles apóiam o reacionário Bolsonaro. Esquerda Diário, 03 out. 2018. Disponível em: <http://www.esquerdadiario. com.br/Conheca-alguns-dos-homens-mais-ricos-do-pais-e-por-que-eles-apoiam-o-reacionarioBolsonaro>. Acesso em: 37 mar. 2019.

PRESIDENTE do grupo Condor firma acordo com MPT-PR e se compromete a divulgar nota de esclarecimento sobre carta encaminhada a trabalhadores. Portal do Ministério Público do Trabalho no Paraná, 02 maio 2018. Disponível em: <http://www.prt9.mpt.mp.br/informe-se/noticias-dompt-pr/45-noticias-prt-curitiba/1 125-presidente-do-grupo-condor-firma-acordo-com-mpt-pr-e-secompromete-a-divulgar-nota-de-esclarecimento-sobre-carta-encaminhada-a-trabalhadores $>$. Acesso em: 29 mar. 2019.

RACY, Sônia; SCARAMUZZO, Mônica. Empresários defendem apoio a Alckmin. Estadão, 17 jul. 2018. Disponível em: <https://politica.estadao.com.br/noticias/eleicoes,empresarios-defendemapoio-a-alckmin,70002352920>. Acesso em: 02 maio 2019. 
REBELLO, Aiuri; PRAZERES, Leandro. Empresas de 4 dos 5 maiores doadores eleitorais devem R\$ 17 milhões à União. Uol, 21 set. 2018. Disponível em: <https://noticias.uol.com.br/politica/ eleicoes/2018/noticias/2018/09/21/empresarios-doacao-campanha-eleicoes-2018-dividauniao.htm?cmpid=copiaecola>. Acesso em: 29 mar. 2019.

REDE Coco Bambu, que doou para a campanha de Bolsonaro, foi condenado por copiar cardápio de concorrente. Fórum, 26 set. 2018. Disponível em: <https://www.revistaforum.com.br/rede-cocobambu-que-doou-para-a-campanha-de-bolsonaro-foi-condenada-por-copiar-cardapio-deconcorrente/>. Acesso em: 28 mar. 2019.

SCARAMUZZO, Mônica; SCHELLER, Fernando. Alckmin tem qualidades para assumir, diz fundador do grupo Cosan. Exame, 31 dez. 2018. Disponível em: <https://exame.abril.com.br/brasil/ alckmin-tem-qualidades-para-assumir-diz-fundador-do-grupo-cosan/>. Acesso em: 2 maio 2019.

SCRIVANO, Roberta. Em comemoração à prisão de Lula, curso para advogados dá desconto de 12\%. O Globo, 06 abr. 2018. Disponível em: <https://oglobo.globo.com/brasil/em-comemoracao-prisaode-lula-curso-para-advogados-da-desconto-de-12-2-22565254>. Acesso em: 28 mar. 2019.

SERNA, Miguel; BOTINELLI, Eduardo. El poder de las élites empresariales en la política latinoamericana. Megafón, n.15/2, ago. 2017. Disponível em: <http://www.cepalforja.org/ dypbuenvivir/wp-content/uploads/2018/06/Migel-Serna-e-Eduardo-Botinelli-El-poder-de-las-élitesempresariales-en-la-política-latino-americana.pdf>. Acesso em: 28 mar. 2019.

SETO, Guilherme. Exaltada por Doria, bandeira com marca infringe lei Cidade Limpa. Folha de $S$. Paulo, 13 fev. 2018. Disponível em: <https://www1.folha.uol.com.br/cotidiano/2018/02/exaltadapor-doria-bandeira-com-marca-infringe-lei-cidade-limpa.shtml>. Acesso em: 23 maio 2018.

TEIXEIRA, Lucas Borges. Burger King faz comercial contra voto em branco: "queremos causar reflexão". UOL, 01 out. 2018. Disponível em: <https:/economia.uol.com.br/noticias/redacao/ 2018/10/01/burger-king-faz-comercial-contra-voto-em-branco-queremos-causar-reflexao.amp.htm>. Acesso em: 30 mar. 2019.

TRABALHADORES do Carrefour são demitidos por entrarem em greve pelos seus direitos. Esquerda Diário, 21 dez. 2017. Disponível em: <http://www.esquerdadiario.com.br/Trabalhadores-doCarrefour-sao-demitidos-por-entrarem-em-greve-pelos-seus-direitos>. Acesso em: 30 mar. 2019.

TRIBUNAL SUPERIOR ELEITORAL (TSE). Divulgação de candidaturas e contas eleitorais. Portal do Tribunal Superior Eleitoral, 2018. Disponível em: <http://www.tse.jus.br/eleicoes/eleicoes2018/divulgacandcontas\#/>. Acesso em: 07 mar. 2020.

ZONA ELEITORAL: TSE recebe 20 pedidos de candidaturas avulsas à presidência. Sul 21, 29 ago. 2018. Disponível: <https:/www.sul21.com.br/zona-eleitoral/2018/08/zona-eleitoral-tse-recebe-20pedidos-de-candidaturas-avulsas-a-presidencia/>. Acesso: 29 mar. 2019.

Texto recebido em 31 de agosto de 2019. Aprovado em 12 de março de 2020. 